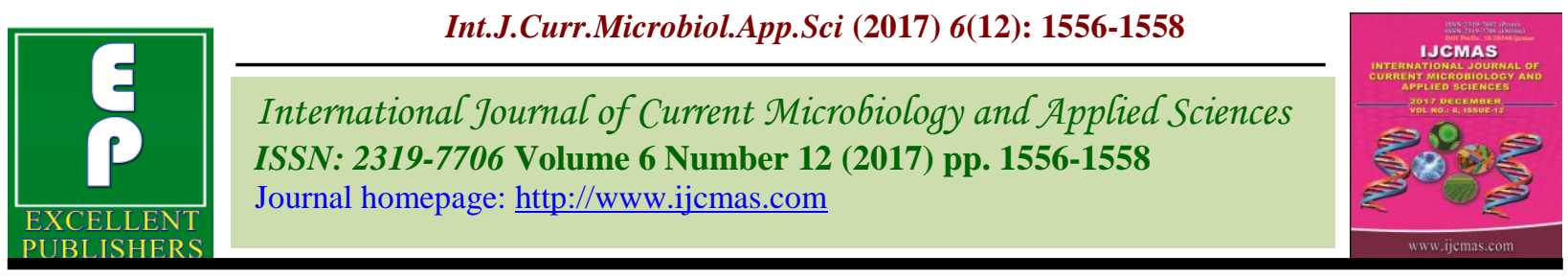

Case Study

https://doi.org/10.20546/ijcmas.2017.612.174

\title{
Facklamia hominis: A Rare Case of Liver Abscess
}

\author{
Rameena Anver* and U. Pratibha Bhat \\ Department of Microbiology, KS Hegde Medical Academy, Deralakatte, \\ Manglore-575018, Karnataka, India \\ *Corresponding author
}

\begin{tabular}{|c|c|}
\hline \multicolumn{2}{|r|}{ A B S T R A C T } \\
\hline Keywords & \\
\hline $\begin{array}{l}\text { Facklamia hominis, } \\
\text { Pyogenic liver } \\
\text { abscess. }\end{array}$ & \multirow{3}{*}{$\begin{array}{l}\text { Facklamia species are gram positive cocci reported in } 1997 \text {. They are alpha } \\
\text { haemolytic facultative anaerobes resembling streptococcus in } 5 \% \text { sheep } \\
\text { blood agar. Facklamia hominis is the most common species of the six } \\
\text { species so far described. Its natural habitat is speculated to be female } \\
\text { genital tract, we report a case of liver abscess caused by the bacterium } \\
\text { Facklamia hominis in a } 54 \text { year male patient who was treated successfully. }\end{array}$} \\
\hline Article Info & \\
\hline $\begin{array}{l}\text { Accepted: } \\
\text { 12 October } 2017 \\
\text { Available Online: } \\
\text { 10 December } 2017\end{array}$ & \\
\hline
\end{tabular}

\section{Introduction}

Pyogenic liver abscess was first described by Hippocrates around 400BC. Most of the cases are polymicrobial, and the microbiology varies in each case. Clinical presentation is mostly non-specific. $70-80 \%$ of aspirates usually give a culture positive report. Pyogenic liver abscess with Facklamia hominis is not yet reported. We are presenting a case of pyogenic liver abscess in a 54 year old male patient, where the pus culture yielded the growth of alpha haemolytic catalase negative cocci identified as Facklamia hominis.

\section{Case history}

A 54 year old male came to the emergency department with severe pain. In the epigastrium and right hypochondrium radiating to right lower back since 2 weeks. He had high fever with chills and rigors. But there was no associated symptoms like vomiting, haematemesis, diarrhoea, pruritis or icterus. He was a heavy smoker and alcoholic. There was no history of DM, HTN, TB. On general examination he was febrile and there was significant distension of abdomen. Liver was palpable almost 2 finger breadth below the costal margins. Routine blood investigation showed a total leucocyte count of 9900 cells/cmm, $\mathrm{Hb} 9.1 \mathrm{gm} / \mathrm{dl}$ and ESR 90 $\mathrm{mm} / \mathrm{hr}$. Peripheral smear showed a normochromic normocytic anaemia USG showed an enlarged liver with fatty changes. There was a mass compressing the left lobe of liver. Gall bladder wall was thickened and 
there was a cystic lesion of $3.5 \times 1.5 \mathrm{~cm}$ size at the base of the GB fossa, with no vascularity. Empirical treatment was started with oral Oflox OZ 200/500 (ofloxacin and ornidazole).

Repeat USG showed an echogenic thick walled collection extending from the left lobe of liver suggestive of sub-capsular rupture of hepatic abscess. Drainage of abscess was done (USG guided) and two samples of pus were sent to microbiology laboratory for culture and sensitivity.Gram stain from both the samples showed numerous pus cells and gram-positive cocci in pairs and chains.

Culture yielded growth in blood agar plates within $24 \mathrm{hrs}$ of incubation. Colonies were alpha haemolytic and catalase negative. The organism showed a growth in $6.5 \% \mathrm{NaCl}$.
Organism identification was done by Vitek 2 automated systems and identified as Facklamia hominis. Conventional AST was done as per CLSI guidelines for Streptococcal spp (ampicillin, benzylpenicillin, gentamicin, ciprofloxacin, cefotaxime, ceftriaxone, clindamycin, erythromycin, levofloxacin, tetracycline, trimethoprimsulphamethoxazol). It was sensitive to all the tested antibiotics.

Facklamia hominis was susceptible to ceftriaxone and IV ceftriaxone was started. He responded well to ceftriaxone (1.5 gm iv injections twice daily along with metrogyl $500 \mathrm{mg}$ iv bd for 1 week). Patent improved clinically, general condition was normal and he got discharged after 10 days and advised to continue oral antibiotics for 10 days (ciplox tz-ciprofloxacin tinidazole).

Table.1 Worldwide human infection with Facklamia hominis

\begin{tabular}{|c|c|c|c|c|c|}
\hline $\begin{array}{l}\text { NO OF } \\
\text { PATIENTS } \\
\text { (COUNTRY) }\end{array}$ & SEX & $\begin{array}{l}\text { POSITIVE } \\
\text { SAMPLES }\end{array}$ & $\begin{array}{l}\text { IDENTIFICATION } \\
\text { METHODS }\end{array}$ & ANTIBIOTIC THERAPY & RESULT \\
\hline $\begin{array}{l}6(\text { Sweden } 5 \\
\text { France } 1)\end{array}$ & $\begin{array}{l}\mathrm{F} \\
2 \mathrm{NA}\end{array}$ & $\begin{array}{l}1 \quad \text { URINE, } 1 \\
\text { VAGI } \\
\text { NAL, } 1 \text { BLOOD, } \\
1 \text { ABSCESS }\end{array}$ & $\begin{array}{l}\text { Characterization } \\
\text { by API rapid ID32 } \\
\text { And API ZYM }\end{array}$ & N/A & N/A \\
\hline $\begin{array}{l}2 \text { United } \\
\text { Kingdom }\end{array}$ & $2 \mathrm{~F}$ & $\begin{array}{l}\text { Blood, Placental } \\
\text { Tissue, Gastric } \\
\text { Aspiration }\end{array}$ & N/A & $\begin{array}{l}\text { Co-amoxiclav, } \\
\text { Ampicillin, } \\
\text { Teicoplanin, Gentamycin, Cefotaxime }\end{array}$ & Cured \\
\hline 1 India & $\mathrm{M}$ & Blood & Vitek 2 systems & Penicillin, Gentamycin, Ceftriaxone & Cured \\
\hline 1 Spain & $\mathrm{F}$ & $\begin{array}{l}\text { Sample from joint } \\
\text { pseudo capsule }\end{array}$ & $\begin{array}{l}\text { Vitek } 2 \text { systems, } \\
\text { 16sRNA PCR }\end{array}$ & $\begin{array}{l}\text { Vancomycin, Gentamycin, Ceftriaxone, } \\
\text { Amoxicillin }\end{array}$ & Cured \\
\hline $\begin{array}{l}1 \text { United } \\
\text { Kingdom }\end{array}$ & NA & Blood & NA & $\begin{array}{l}\text { Amoxicillin+Clavulonic } \\
\text { Vancomycin, } \\
\text { Gentamycin }\end{array}$ & Died \\
\hline 1 France & $\mathrm{F}$ & Abscess & MALDI-TOF & Pristinamycin & N/A \\
\hline
\end{tabular}

\section{Results and Discussion}

Facklamia species are gram positive cocci first described in 1997 by Collins et al. They are alpha haemolytic facultative anaerobes, resembling Streptococcus viridans on 5\% sheep blood agar. Natural habitat of Facklamia species is the female genital tract and the majority of clinical isolates are from females.The transmission and source of infection in male cases are still unclear. Management of systemic infection with
Facklamia spp is still challenging due to its diverse antibiotic susceptibility pattern ${ }^{5}$.Our case identification was done by Vitek 2 systems using gram positive calorimetric card of 64 test substrates.

So far very few cases of human infection have been identified for Facklamia species. The bacteria was isolated from placenta, mitral valve, joints, scapular abscess, cerebrospinal fluid and vaginal swab. Most of these are susceptible to beta lactams. 
This case report gives us a chance to emphasize that Facklamia hominis is becoming an emerging pathogen and the need for further studies on this rare organism. Further reporting will help us to generate better knowledge to determine the clinical significance and management.

\section{References}

Abat, C., V Garcia, JM Rolain. Facklamia hominis scapula abscess Marsielle, France. New Microb and New Infection. 2016; 9: 1314.

Ananthakrishna R, Shankarappa RK, Jagadeesan N, Math RS, Karur S, Nanjappa MC. Infective endocarditis: A rare organism in an uncommon setting. Case Rep Infect Dis. 2012; 2012: 307852.

Collins MD, Falsen E, Lemozy J, Akervall E, Sjoden B, Lawson PA. Phenotypic and Phylogenetic Characterization of some
Globicatella- like organism from human sources: Description of Facklamia hominis gen. nov, sp.nov. International journal of Systemic Bacteriology. 1997Jul; 47(3): 880-882.

Corona PS, Haddad S, Andres j, GonzalezLopez JJ, Amat C, Flores X. Case report: First report of a prosthetic joint infection caused by Facklamia hominis. Diagn Microbiol Infec Dis. 2014 Dec; 80(4): 338-40.

LaClaire, L., and R. Facklam. Antimicrobial Susceptibilities and Clinical Sources of Facklamia species. Antimicrobial Agents and Chemotherapy. 44(8): 21302. September 2000.

Parvataneni KC, Iyer S, Khatib R, Saravolatz LD. Facklmia species and Streptococcus pneumonia Meningitis: A case report and review of literature. Open forum infect dis. 2015 Mar 23; 2(2).

\section{How to cite this article:}

Rameena Anver and Pratibha Bhat, U. 2017. Facklamia hominis: A Rare Case of Liver Abscess. Int.J.Curr.Microbiol.App.Sci. 6(12): 1556-1558.

doi: https://doi.org/10.20546/ijcmas.2017.612.174 